\title{
Lição crítica: Roland Barthes e a semiologia do impasse
}

Marcio Renato Pinheiro da Silva

Ao que parece, o ensaísta francês Roland Barthes está de volta. De fato, é difícil dizer se, desde meados da década de 1950, houve algum momento em que Barthes esteve ausente, especialmente para os estudos literários. De qualquer modo, é notável que, a partir de 2002, circunstâncias, a princípio, editoriais o tenham trazido de volta. Na França, há, de um lado, a reedição, corrigida e aumentada, de suas obras completas; de outro, a publicação das inéditas anotações dos cursos que Barthes ministrou, entre 1977 e 1980, no Collège de France. Acrescente-se ainda, sobretudo na França e nos Estados Unidos, a reedição de alguns estudos críticos dedicados à sua obra ou à publicação de inéditos afins. No Brasil, a partir dessa mesma época, têm surgido colóquios dedicados a Barthes, reedições de seus livros em novas traduções ou publicações inéditas, além de alguns estudos críticos. Tudo isso ou incita à retomada do trabalho de Barthes, ou este é por tal retomada incitado.

E quem está em voga em tal retomada é "um sujeito incerto, do qual cada atributo é, de algum modo, combatido por seu contrário"*1. Não por acaso, alguns dos adjetivos que costumam caracterizar sua trajetória intelectual são: antagônico, infiel, contraditório, paradoxal. Ainda que muitos sejam os desvios aí traçados, um deles, particularmente, sobressai-se, seja por sua evidência e difusão, seja porque, a partir dele, os demais podem ganhar contornos mais nítidos. Trata-se da relação de Barthes com a semiologia, isto é, com a ciência que, baseada na lingüística estrutural, pretende sistematizar con-

1 Todas as citações de Barthes utilizadas neste artigo pertencem a essa segunda edição de suas obras completas. Daqui por diante, as referências serão fornecidas por meio de algarismos romanos, indicativos do tomo (de I até V), e de algarismos arábicos, indicativos das páginas, ambos antecedidos pelo título, entre aspas, da publicação a que se referem. As traduções para a língua portuguesa, fornecidas no corpo do texto, são de minha autoria.
* "un sujet incertain, dans lequel chaque attribut est en qualque sorte combattu par son contraire" (Barthes, Roland. "Leçon". Em: CEuvres complètes, t. V. $2^{\text {a }}$. ed. Paris: Seuil, 2002: 429.) 
ceitos e métodos aptos à sondagem da significação no seio da vida social.

De Mitologias, de 1957, até, aproximadamente, O sistema da moda, de 1967, cerca de dez anos, portanto - este é o período em que Barthes se dedica, categoricamente, à semiologia. Mitologias, de certo modo, "dispensa apresentações". Suas leituras da cultura de massa dos anos 1950 são, desde então, célebres. Até hoje, o livro é um importante parâmetro para leituras afins, como, por exemplo, algumas daquelas praticadas pelos estudos culturais. Já com $O$ sistema da moda, tudo se passa de outra maneira. De um lado, suas reflexões teóricas são consideradas demasiadamente rígidas e truncadas, longe da concisão e do didatismo de Elementos de semiologia, de 1965. De outro, seu objeto de estudo, a moda tal como "descrita" pela imprensa especializada, soa, para muitos, algo prosaico, trivial e insignificante, se comparado a Mitologias. Em outras palavras, de um lado, hermetismo teórico, cientificismo; de outro, alheamento sociopolítico - eis o duplo estigma de $O$ sistema $d a$ moda, o mito que o encerra e que, de tão forte, estende-se à semiologia barthesiana como um todo.

Os trabalhos posteriores de Barthes dão mais margem a esse tipo de apreciação. Neles, não busca mais a particularização do geral, a dedução dos diversos processos de significação em um conjunto reduzido de matrizes. Ao contrário, o que se empreende é a generalização do particular, a distensão das significações de um dado texto até o ponto em que elas podem ser, também, encontradas e continuadas, de forma nãocumulativa, em outros textos (intertextualidade), e assim sucessivamente. É possível sim dizer que essa distensão da significação se pauta em parâmetros semiológicos, mas, nesse caso, a semiologia se torna um conjunto heterogêneo de operadores de leitura, de ferramentas que se prestam não necessariamente à articulação de relações abstratas estáveis e extensíveis a diferentes sistemas, mas ao estilhaçamento e à prorrogação da significação.

Por isso, O sistema da moda parece ser o último empenho de Barthes em estabelecer a semiologia como ciência. Ainda que, como dito, nos trabalhos posteriores do ensaísta seja possível atribuir um papel concatenador aos parâmetros semiológicos, O sistema da moda assinala, pelo menos, o fim de um dos ciclos dos estudos semiológicos barthesianos. Por mais 
que se caracterizem pela ênfase dada à sistematização rigorosa de diversos processos de significação, é possível encontrar nos trabalhos desse primeiro ciclo a previsão do ulterior deslocamento das pesquisas semiológicas, bem como reflexões crítico-teóricas afins, ou seja, nesses trabalhos, além da projeção do impasse da semiologia, há uma espécie de estudo semiológico desse impasse. Disso decorre o objetivo deste

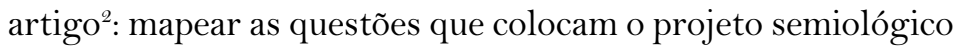
em xeque, de acordo com a própria semiologia.

Para tanto, há, em um primeiro momento, uma sucinta caracterização dos estudos semiológicos de Barthes, com ênfase em seus possíveis objetivos e funções. A partir disso, desdobram-se a configuração do impasse em que se vê a semiologia e o estudo semiológico desse impasse.

\section{Fins semiológicos}

Antes de tudo, cumpre reiterar que a semiologia desse primeiro ciclo é uma ciência (em construção) que, baseada na lingüística estrutural, estuda a significação no seio da vida social, sendo significação o processo de composição dos signos, de assimilação de um significante a um significado. Há, assim, uma dupla necessidade permeando os estudos semiológicos. De um lado, a revisão dos pressupostos crítico-teóricos da lingüística estrutural visando à compreensão da significação em diversas linguagens. Do outro, a assimilação de reflexões sócio-históricas a essa revisão, já que a significação estudada acontece, como dito, em meio à vida social.

Essa revisão da lingüística estrutural por meio também de sua assimilação a questões de ordem social e histórica tem duas implicações interdependentes. Sendo a significação um acontecimento sobretudo social, estudá-la como tal faz com que a semiologia, de algum modo, adquira certa função na sociedade. No caso de Barthes, apesar de justificar e de motivar a pesquisa semiológica, essa função também é, e desde

${ }^{2}$ Este artigo consiste na retomada e na ampliação da comunicação oral intitulada "A revolta semiológica de Roland Barthes", apresentada, em 25 de junho de 2004, no III Simpósio de Linha de Pesquisa: Perspectivas Teóricas no Estudo da Literatura, promovido pelo Programa de Pós-Graduação em Letras da UNESP, campus de São José do Rio Preto-SP. Esclarece-se que tanto esta comunicação quanto o presente artigo contam com o apoio do Conselho Nacional de Desenvolvimento Científico e Tecnológico (CNPq). 
* "tout système sémiolo. gique est un système de valeurs; or le consomma teur du mythe prend la signification pour un système de faits: le mythe est lu comme un système factue alors qu'il n'est qu'un sys tème sémiologique" ("My thologies", 1:843).

" (Marx, Karl \& Engels, Frie drich. A ideologia alemã. 2 ed. São Paulo: Martins Fontes, 1998). o princípio, um fenômeno de significação, mesmo porque se a significação é um fenômeno social, isso acontece porque, para a semiologia, a própria sociedade não deixa de ser um fenômeno de significação, bem como as funções que, eventualmente, são aí desenvolvidas.

Já em Mitologias, primeiro trabalho assumidamente semiológico de Barthes, pratica-se a conjunção entre os pólos lingüístico e social, a partir da qual se articula uma possível função para os estudos semiológicos. Aí, estuda-se o mito, isto é, o processo semiológico praticado em torno de uma determinada classe, no caso, da burguesia. Para Barthes, o mito é o fenômeno semiológico que oblitera seus vínculos sociais, políticos e históricos para que seus valores sejam apresentados como algo factual: "todo o sistema semiológico é um sistema de valores; ora, o consumidor do mito toma a significação por um sistema de fatos: o mito é lido como um sistema factual, ao passo que ele é, apenas, um sistema semiológico"* Trata-se da indiscriminada proliferação de valores burgueses na cultura de massa dos anos 1950 (filmes, jornais, espetáculos, programas de televisão, política etc.), que naturaliza esses valores, tornando-os fatos por meio dos quais a sociedade concebe e sanciona a si mesma.

$\mathrm{O}$ conceito de mito de que Barthes se vale guarda certa relação com Marx e Engels, e também com Nietzsche. Esses vínculos podem não só reforçar e ampliar a função da Semiologia, como também elucidar alguns dos aspectos que acenam ao impasse semiológico. Por isso, convém uma breve sondagem de tais relações.

No primeiro caso, o mito pode ser lido como afim à ideologia, tal como Marx e Engels a concebem, sendo que sua primeira elaboração consta de $A$ ideologia alemã $\tilde{x}^{*}$ A ideologia é, basicamente, uma consciência equivocada. Equivocada porque, à luz da incompreensão das contradições sociais e históricas em meio às quais se encontra uma determinada classe, todos os problemas dessa classe são atribuídos a outras instâncias que não aos fatores considerados reais, no caso, às conjecturas materiais próprias a uma sociedade de classes. Essa atribuição dá vazão a uma série de valores e de preceitos, com base nos quais essa classe pensa a si mesma e sobre as demais. A ideologia não é algo que uma classe manipula ou calcula conscientemente, embora as tentativas de mani- 
pulação que visam a necessidades imediatas tenham base na ideologia, sejam uma espécie de ideologia degradada. Por fim, tanto a ideologia quanto as tentativas de manipulação por meio dela são relativas à classe dominante, àquela que detém a propriedade e o controle sobre os modos de produção. É a partir dessa classe que tanto a ideologia quanto as tentativas de manipulação se disseminam socialmente. O mito de Barthes, fenômeno semiológico tomado por factual, pode ser assimilado, justamente, a essa disseminação, como sendo a ideologia veiculada pela cultura de massa da época.

Quanto a Nietzsche, é pertinente a menção de parte do vigésimo primeiro parágrafo de Além do bem e do mal:

Não se deve coisificar erroneamente "causa" e "efeito" [...]; deve-se utilizar a "causa", o "efeito", somente como puros conceitos, isto é, como ficções convencionais para fins de designação, de entendimento, não de explicação. No "em si” não existem "laços causais”, "necessidade", "não-liberdade psicológica”, ali não segue "o efeito à causa”, não rege nenhuma "lei”. Somos nós apenas que criamos as causas, a sucessão, a reciprocidade, a relatividade, a coação, o número, a lei, a liberdade, o motivo, a finalidade; e ao introduzir e entremesclar nas coisas esse mundo de signos, como algo "em si", agimos como sempre fizemos, ou seja, mitologicamente.

Nietzsche considera que a articulação de uma relação causal (princípio de razão suficiente), base de qualquer especulação considerada lógica, equivale, em certa medida, à sua criação, sendo esta motivada pela necessidade, contingente e específica, de entendimento e/ou designação. A obliteração dessa necessidade visa à transposição da relação causal para um nível aquém de qualquer determinação ("em si”), “coisificando” (reificando) tal relação, tornando-a, em vez de determinada, determinante, isto é, um mito.

A mitologia nietzscheana parece ser mais de ordem lógica que afim às ambivalências próprias a uma sociedade de classes. Ainda assim, tanto a mitologia de Nietzsche quanto a ideologia de Marx e de Engels configuram um mesmo gesto, próprio ao mito barthesiano. Pode-se dizer que esse gesto consiste no deslocamento da contingência rumo à construção de uma transcendência que, em seguida, é tomada por causa, por explicação de qualquer contrariedade. Cria-se, então, um "efeito de esclarecimento", de compreensão coerente e pertinente, quando, de fato, trata-se de um esclarecimento equivocado, pautado em ilações, em "saltos" de consistên-
"(Nietzsche, Friedrich. Além do bem e do mal: prelúdio a uma filosofia do futuro. Tradução de Paulo César de Souza. 2. ed. São Paulo: Companhia das Letras, 1992 27 , aspas e grifos do autor) 
- "la société [...] parle les signifiants du système considéré, tandis que le sémiologue parle ses signifiés; il semble donc possé der une fonction objective du déchiffrement [...] face au monde qui naturalise ou masque les signes" ("Elé ments de sémiologie", II: 698).
" "Moins terrorisée par le spectre du 'formalisme', la critique historique eût été peut-être moins stérile; [...] plus um système est spéci. fiquement défini dans ses formes, et plus il est docile à la critique historique" ("Mythologies", I: 825-6). cia dubitável. Esse efeito alicerça uma dada compreensão daquilo que é concebido como sendo a realidade, compreensão cujo domínio (consciente ou não; geralmente, não o é) viabiliza sanções de toda ordem (lógico-cognitiva e lingüística, sociopolítica, econômica etc.). Por meio dessas sanções, estruturam-se hierarquias diversas, que se prestam à legitimação e ao exercício do poder por parte das instâncias ligadas ao mito. Essas instâncias são, certamente, classes, mas também qualquer outra, digamos, comunidade discursiva. Tratase, em suma, de um gesto sociopolítico e histórico (ideológico) porque de ordem lógica e cognitiva (mitológica), ou vice-versa.

Como o mito barthesiano diz respeito à cultura de massa dos anos 1950, não é difícil pressupor que a massificação desse processo torna tudo mais e mais complexo, mais e mais disseminado. Essa, provavelmente, é uma das razões que levam Barthes a considerar, no fim de Elementos de Semiologia, que "a sociedade [...] fala os significantes do sistema considerado, enquanto o semiólogo fala os significados desse mesmo sistema; o semiólogo parece, assim, possuir uma função objetiva do deciframento [...] diante do mundo que naturaliza ou mascara os signos"*. Ou seja, aí, o mito transpõe a cultura de massa, generaliza-se, torna-se assimilável praticamente a toda e qualquer significação tal como em voga socialmente. Em face dessa generalização do mito, Barthes concebe o trabalho do semiólogo como um ato político, uma vez que visa desfazer o dogmatismo e o pragmatismo que alheiam a sociedade dos valores que a estruturam, isto é, de sua própria linguagem.

O crescente rigor com que os estudos semiológicos sistematizam os processos de significação parece ser diretamente proporcional à generalização do mito, rigor cuja motivação é tanto científica quanto política: "Menos aterrorizada pelo espectro de um certo 'formalismo', a crítica histórica teria sido, possivelmente, menos estéril; [...] quanto mais um sistema é definido, especificamente, em suas formas, mais dócil é à crítica histórica"*. Em suma, uma maior percepção da proliferada incidência do mito leva a semiologia a um maior apuro metodológico.

Tal apuro pressupõe não só a revisão dos métodos semiológicos, mas também dois outros fatores. Em primeiro lugar, desencadeia-se a repetição e a reiteração contínuas do dis- 
curso semiológico, revisado ou não. A partir disso, o repetido ganha contornos, em muito, gregários, de modo que se tende à naturalização da significação no seio da vida social como sendo, digamos, alienada, da mesma maneira que à da semiologia como sendo um meio de esclarecimento crítico, um discurso de boa consciência. Eis, aí, o mito em estado latente.

Mas os estudos semiológicos barthesianos têm em mente diversas outras questões que concorrem à reavaliação da semiologia, antes mesmo de sua eventual mitificação nos termos acima expostos. E são essas questões aquilo a que, agora, convém atentar.

\section{O impasse}

Em um trecho de Mitologias, Barthes escreve que "o vinho é, objetivamente, bom, e, ao mesmo tempo, a bondade do vinho é um mito: eis a aporia"*. Esse movimento metonímico, segundo o qual o qualificativo (bondade) é tomado pelo qualificado (vinho), desencadeia, de fato, uma aporia, um impasse. De um lado, só se pode tomar alguma coisa qualquer pela experiência que se tem dela, isto é, por sua qualificação, por sua significação. De outro, essa experiência tende a suplantá-la. Com efeito, a experiência que se tem de algo se dá, em certa medida, ao custo da refração desse algo.

Barthes diz que o semiólogo "lida com isso como pode: ele se ocupará da bondade do vinho, não do próprio vinho"*. Há, como já visto, uma função sociopolítica subjacente ao esclarecimento da bondade do vinho como mito, isto é, da significação como mito. A significação, entretanto, tende a suplantar aquilo a que, em tese, refere-se, nesse caso específico, o vinho. Sendo assim, compreender a significação como sendo um mito e, então, desmitificá-la acaba dissipando boa parte do que o semiólogo concebe por vinho.

Desse modo, feita a desmitificação, o que resta para o semiólogo? "O próprio vinho", poder-se-ia dizer. Mas boa parte desse "o próprio vinho", ao menos a parte que compete à semiologia e ao semiólogo, foi posta em xeque pela desmitificação. Para o semiólogo, então, "o próprio vinho" não é mais vinho nem significação. Ou melhor, não é mais vinho justamente por não ser mais significação.

Feita a desmitificação, o semiólogo poderia conferir alguma significação ao vinho em termos considerados não-mi-
* "[...] le vin est objective ment bon, et en même temps, la bonté du vin est un mythe: voilà l'aporie" ("Mythologies", I: 868, grifo do autor).

* "sort de là comme il peut: il s'occupera de la bonté du vin, non du vin lui-même" ("Mythologies", l: 868.) 
" "est d'ordre sarcastique" ("Mythologies", I: 867).

- "la positivité de demain est entièrement cachée par la négativité d'aujourd'hui; toute les valeurs de son enterprise lui son données comme des actes de des. truction: les uns recouvrent exactement les autres, rien ne dépasse" ("Mythologies", I: 867).

* "est condamné au méta-lan gage" ("Mythologies", I: 867)

' "aucune substance 'vraie', qui serait à porter tout en tière au crédit de l'analyste, mais seulement une vali. dité formelle" ("Système de la mode", II: 1191, grifo do autor).

- "c'est nullement une es. sence abstraite, purifiée c'est une condensation in forme, instable, nébuleuse, dont l'unité, la cohérence tiennent surtout à la fonc tion" ("Mythologies", I: 832).

* "nous n'arrivions pas à dé. passer une saisie instable du réel" ("Mythologies", I: 868) tológicos - por exemplo, dizer, como na citação já transposta, que “o vinho é, objetivamente, bom”. Mas, nesse caso, como sugere Barthes, ocorreria a restauração das condições necessárias à arquitetação do mito, uma espécie de mito em devir, de modo que haveria o risco não só de invalidação da desmitificação, bem como de o semiólogo, voluntariamente ou não, endossar o mito.

O que resta, afinal, para o semiólogo?

Barthes diz que a relação do semiólogo com a sociedade "é de ordem sarcástica"*. Por isso, o que lhe resta é um amanhã, um tempo que, em seu presente, não é, e cujo futuro parece menos uma certeza que uma aposta, um risco: "a positividade do amanhã está oculta, inteiramente, sob a negatividade do hoje; todos os valores de seu empreendimento se lhe apresentam como atos de destruição: aqueles são recobertos por estes, nada restando"*. E as fichas que o semiólogo aposta, as únicas, aliás, que ele possui, são seu trabalho, ou seja, sua linguagem: ele "está condenado à metalinguagem"*.

Há algo mais delicado ainda. A aposta da metalinguagem é uma tentativa de transformá-la: no momento em que faz a aposta, o semiólogo já a perdeu, já que ela não tem mais validade: com relação ao objeto de estudo, a metalinguagem não possui “qualquer substância 'verdadeira' que se poderia creditar ao analista, mas apenas uma validade formal"*. A metalinguagem "não é, absolutamente, uma essência abstrata, purificada; é uma condensação informe, instável, nebulosa, cuja unidade e cuja coerência advêm, sobretudo, de sua função"** Barthes diz que tal instabilidade da metalinguagem acontece porque "não conseguimos ir além de uma apreensão instável do real”* Talvez também porque a transitoriedade seja própria ao real tal como o semiólogo o concebe, no caso, como significação, como sentido em processo. Nesse sentido, adequar a metalinguagem ao objeto de estudo, que é instável, pode ser uma precondição à validade da metalinguagem e, ao mesmo tempo, à sua invalidade futura.

Em tese, o que confere "validade formal" e "função" à metalinguagem não deixa de ser um gesto hierárquico que toma por parâmetro a própria semiologia. A validade é legitimada àqueles que conhecem e dominam a semiologia e tudo aquilo que ela implica, não por acaso, aqueles que a articulam, ou seja, os semiólogos. Mas nos estudos semiológicos, nos de Barthes pelo menos, esse não é um gesto sub-reptício. 
É apenas algo considerado próprio ao saber humano, uma vez que ele "está condenado a confundir a verdade com a linguagem"*. Sendo assim, em termos semiológicos, o conceito de validade diz respeito a uma assimilação temporária, equivocada mas necessária, da verdade à linguagem. Não por acaso, o que permite ao semiólogo julgar a significação na vida social como mito é justamente um outro mito, no caso, a própria metalinguagem semiológica: o semiólogo só pode desmitificar conforme mitifica em outro âmbito, conforme desloca mitos.

Mas há uma diferença entre a metalinguagem das pesquisas semiológicas de Barthes e o mito que lhe serve de objeto de estudo. O mito oblitera sua condição de significação para se autopromover como verdade. A metalinguagem semiológica não deixa de fazer o mesmo, mas o faz na mesma medida em que antevê seu próprio esgotamento: "Há, aí, uma necessidade que o Estruturalismo tenta, precisamente, compreender, isto é, falar: o semiólogo é aquele que exprime sua futura morte por meio dos mesmos termos com os quais nomeou e compreendeu o mundo"*. O semiólogo precisa assimilar sua metalinguagem à verdade, visto que, sem essa operação, não há metalinguagem, nem semiologia. Ao fazê-lo, a metalinguagem ganha função e validade, bem como a semiologia e o semiólogo. Mas a função e a validade só são viáveis se, concomitantemente à sua instauração, são instauradas também as condições necessárias à sua disfunção e à sua invalidade.

Para a semiologia, não há como ser diferente, pois “o saber humano só pode participar da transformação do mundo por meio de uma série de sucessivas metalinguagens, cada qual alienada no instante que a determina”* . A metalinguagem da Semiologia “se torna, portanto, provisória em razão da própria história que renova as metalinguagens”*. De modo que "a história das Ciências Humanas seria, assim, em certo sentido, uma diacronia de metalinguagens, e cada ciência, inclusive, é claro, a Semiologia, conteria sua própria morte, sob forma da linguagem que a falará”* Novamente, só resta ao semiólogo e à semiologia um amanhã no qual ambos, em princípio, figurarão não como quem fala, mas como de quem se falará. E, de fato, mais de trinta anos após a publicação desses textos, muitos dos leitores de Barthes confirmaram e confirmam, ainda que de maneira muitas vezes involuntária, as previsões do ensaísta.
" "il est condamné à confon dre la vérité et le langage" ("Système de la mode", II: 1192).

" "Il y a là une nécessité que le structuralisme essaye précisément de compren. dre, c'est-à-dire de parler: le sémiologue est celui qui exprime sa mort future dans les termes mêmes où il a nommé et compris le monde" ("Système de la mode", II: 1192.)

- "le savoir humain ne peut participer au devenir du monde qu'à travers une sé rie de métalangages suc. cessifs, dont chacun s'aliène dans l'instant qui le détermine" ("Système de la mode", II: 1191-2).

- "est cependant rendue pro. visoire par l'historie même qui renouvelle les métalan gages" ("Éléments de sé miologie", II: 698).

* "I'histoire des sciences humaines serait ainsi, en un certain sens, une diachronie de méta-langages, et cha que science, y compris bien entendu la sémiologie, con tiendrait sa propre mort sous forme du langage qui la parlera" ("Éléments de sémiologie", Il: 698). 


\section{Contraponto e fuga}

A semiologia barthesiana desse primeiro ciclo é uma prática que se direciona não só a seu objeto de estudo, mas também à própria investigação crítico-teórica, criando a necessidade de revisão e de reinvenção de ambos, da investigação e de seu objeto, e, por que não, do próprio, digamos, sujeito científico, no caso, o semiólogo. Essa revisão e essa reinvenção são uma possível forma de adiar o ocaso da semiologia sob a forma daquela que é falada, para que continue a falar por si mesma, ainda que esse "si mesma" se torne ambíguo em razão de sua revisão e de sua reinvenção. Trata-se, em suma, de uma revolta "contra" a semiologia para que, talvez, melhor se volte a ela e se lhe dê continuidade. Como dito no princípio deste artigo, essa revolta leva Barthes a um estádio que poder ser considerado um segundo ciclo dos estudos semiológicos, no qual a semiologia é, de um lado, uma ferramenta de estilhaçamento e de prorrogação da significação, e, de outro, assume-se, mais ainda, como significação.

Em relação ao impasse a que chega esse primeiro ciclo, parece que sua maior motivação diz respeito a uma certa equivalência entre o discurso crítico e o ideológico, ou, no sentido nietzscheano e barthesiano, mitológico. Não há qualquer fator que garanta a um dado discurso ser considerado crítico ou ideológico/mitológico, senão a função que desempenha em situações específicas, isto é, sua validade. E, sendo a validade algo que pode desencadear a ideologia/mitologia, sua instauração precisa comportar as condições necessárias à sua subseqüente invalidade, um vez que, para a semiologia, a crítica inscreve o desejo do sujeito no mesmo golpe em que castra o objeto de desejo, quando não o próprio sujeito, caso ele se resuma não a seu desejo, mas ao objeto (castrado) desse desejo. Da mesma maneira, a atividade crítica, ao se pretender esclarecedora, aliena o objeto de estudo, assim que considerada válida ou pertinente. Isso porque esse objeto se torna não ele mesmo, mas sim o que dele se diz. O sujeito crítico, caso queira criticar o que se diz do objeto, só poderá dizer outra coisa, a qual também alienará o objeto, assim que considerada válida ou pertinente etc. Trata-se, em suma, de um ciclo gregário, vicioso, que, a cada volta, mais se desprende de seu objetivo inicial (a elucidação da significação na sociedade como mito) rumo à identificação involuntária com seu objeto de estudo. 
Seleção e avaliação, isto é, o desejo da crítica sobreposto a seu objeto de estudo/desejo; em resumo, assertividade: esse é, provavelmente, um dos procedimentos críticos basilares. Vimos, contudo, que seus efeitos podem estar além ou aquém de qualquer atividade que se pretenda crítica. Para Barthes, uma maneira de lidar com esse impasse é enfatizar não a verdade da crítica, mas apenas sua validade. Vimos também que a validade, confusão temporária entre linguagem e verdade, coaduna sua instauração e o devir de sua invalidade. O que seria, mais precisamente, essa confusão entre linguagem e verdade? Como se dá a concomitância entre validade e invalidade? Como isso se relaciona à assertividade, em geral, própria à atividade crítica?

Há dois processos interdependentes. De um lado, a atividade crítica, quando centrada menos no asseverado que na força que desencadeia a asserção e que é desencadeada por ela. De outro, a consciência de que a asserção, apesar de ser um processo semiológico, veicula valores que a aproximam do mito, isto é, do factual; dito de outro modo, o caráter semântico da asserção desencadeia um "efeito" ontológico ao qual é necessário atentar, sendo esse efeito aquilo que confunde linguagem e verdade. Para explicá-lo, tomemos uma pergunta que pode ser uma espécie de motivação crítica elementar: "o que é?” ou, visando a uma maior praticidade metodológica, "o que é mito?”. A pergunta afirma que o termo "mito" não possui sentido, sendo necessário que se lhe esclareça. Obviamente, tal esclarecimento depende, sobretudo, dos valores afins aos interlocutores (que ambos têm ou que lhes são impostos por várias instâncias e de diversas maneiras), daquilo que, aí, for considerado válido ou pertinente. Mas isso só se torna necessário porque o termo "mito", por si só, não possui sentido em tal situação enunciativa - se o tivesse, a pergunta seria desnecessária. Para possuí-lo, entra em cena outro termo (ou mais de um) que não "mito", que é, então, tomado por "mito". Esse termo sobreposto a "mito" só pode desempenhar tal função semântica se outro termo fizer, por ele, o mesmo que ele faz por "mito", e assim sucessivamente. Isso implica que tão ou mais relevante que a própria asserção (os termos eventualmente considerados válidos) é a força que a desencadeia e que é desencadeada por ela. Por isso, a validade de um termo (ou, mesmo, de uma metalinguagem) é temporária ou mesmo contingente, pois ela é menos relativa ao asseverado que ao movimento em meio ao qual ele se instaura. 
Mas a validade depende de uma confusão fortuita entre verdade e linguagem. Essa confusão acontece quando, por meio do exemplo do parágrafo anterior, o termo "mito" e aquele que se lhe sobrepõe suspendem o movimento lingüístico que os desencadeia (e que pode ser desencadeado por eles), dando vazão a uma espécie de alucinação. Nesse caso, os dois termos citados são de tal modo assimilados entre si que se cria a impressão de que, de fato, "mito é X, Y ou Z". Em outros termos, como se também os interlocutores se unissem por meio de uma paixão alucinatória pelas palavras, que implica o rompimento da distância entre as palavras (signos) e as coisas (referentes). Rompimento, esclareça-se, não porque a distância entre uma e outra foi, finalmente, percorrida, mas sim porque ela foi abolida em razão da exclusão de um dos pólos, no caso, as coisas (referentes). Sem os referentes, a verdade é a palavra, os signos; ou vice-versa.

Possivelmente, o sentido acontece mediante tal paixão; o sentido é uma verdade de palavras. Eis o efeito ontológico desencadeado por uma operação semântica, cuja verdade é a de uma identificação entre o sujeito crítico, seu objeto de estudo/desejo e sua linguagem. E todos esses elementos, a linguagem especialmente, implicam a História, as diversas histórias da qual a História é feita e revista - história da linguagem, dos corpos, das idéias, da crítica, da sociedade etc. É por isso que Barthes considera, como vimos, que a validade crítica é afim à verdade do crítico e de seu tempo. E o Barthes crítico sabe que sua verdade está menos nos seus objetos de desejo/de estudo que na força que possibilita a identificação do crítico aos objetos (ou vice-versa). A mesma força que, em breve, trata de suspender essa identificação e de deslocá-la para outros objetos, projetando novos e renovados reencontros. Sem esse deslocamento, o crítico pode recair em mitologia, em ideologia, em paródia involuntária de si mesmo.

Suspender o projeto semiológico, revisá-lo via deslocamento, eis uma tentativa de burlar, ainda que temporariamente (é provável que não haja outro modo), a ideologia e a mitologia. Tentativa, aliás, triplamente crítica. Em primeiro lugar, porque o que a revela não é exatamente a consciência de que a semiologia, ciência da significação ou da linguagem, é, também, como qualquer outra ciência, significação ou linguagem. E as implicações disso são percebidas confor- 
me se intensifica a dedicação à semiologia. Em seguida, porque essa tentativa crítica pressupõe autocrítica, isto é, o despojamento de se reconhecer no objeto de estudo/de desejo (ou de reconhecê-lo em si) e de não se esquivar ante tal reconhecimento, de criticá-lo também. Por fim, a concepção segundo a qual uma tentativa crítica não só abrange a seleção e a avaliação do objeto de estudo, dos métodos/instrumentos (no caso, metalinguagem) e do sujeito crítico, mas também, pode levar a uma situação crítica. E essa situação, ao assinalar o eventual fim (ou revisão, ou deslocamento) de todo um processo crítico, é o que justifica esse processo na mesma medida em que renova sua necessidade.

Ante essa necessidade renovada, ante esse estádio crítico, é possível que não se tenha mais palavras, que, em resposta à pergunta “o que é mito?", só se possa dizer “mito é mito", e que essa resposta seja um vazio rumo ao qual o crítico teme lançar-se. A tautologia, aí, é uma espécie de limite, de suspensão da significação, da permutação entre signos. Nesse ponto, tudo o que se tem é a linguagem, mas ela pode não mais ter validade; nesse ponto, o absurdo, advindo do esgotamento lógico, e a ignorância se equivalem; e precisamente nesse ponto, é possível ainda se lançar a um sim inaudito que aí ressoa:

Uma vez atingido o extremo da linguagem, lá, onde ela nada pode senão repetir sua última palavra, como um disco riscado, embriago-me com sua afirmação: a tautologia não seria aquele estádio inaudito, no qual se reencontram, misturados todos os valores, o fim glorioso da operação lógica, o obsceno da tolice e a explosão do sim nietzschiano?
Ayant atteint le bout du langage, là où il ne peut que répéter son dernier mot, à la façon d'un disque enrayé, je me soûle de son affirmation: la tautologie n'estelle pas cet état inouï, où se retrouvent, toutes valeurs mêlées, la fin glourieuse de l'opération logique, l'obscène de la bêtise et l'explosion du oui nietzschéen?*
(Barthes. Roland. "Frag ments d'un discours amou reux", $v: 50$, grifos do autor).

Talvez essa lição crítica seja, ainda (ou sobretudo) hoje, válida. 
Marcio Renato Pinheiro da Silva

Doutorando em Teoria da Literatura junto ao Programa de Pós-Graduação em Letras da UNESP, campus de São José do Rio Preto (SP), e bolsista do CNPq.

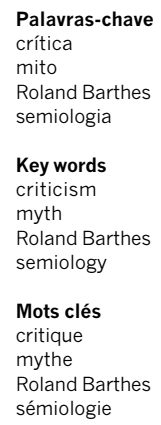

\section{Resumo}

Compreendendo por semiologia a ciência que se dedica ao estudo da significação no seio da vida social, este artigo desenvolve, em um primeiro momento, uma possível função social de tal ciência, de acordo com Roland Barthes. Em seguida, considera a hipótese, segundo a qual a conjunção dessa função com o estudo sistemático da significação acena para um impasse da semiologia, o qual é tanto previsto quanto lido criticamente por Barthes.

\begin{abstract}
Considering that semiology is the science which studies the signification at society, this paper investigates, firstly, a probable social function of such a science, mainly, according to Roland Barthes' work. Secondly, it is considered that the link between this function and the systematic study of signification checkmates semiology, what Roland Barthes itself realizes, dealing with it critically.
\end{abstract}

\section{Résumé}

Entendant que la sémiologie est la science qui étudie la signification au cour de la vie sociale, on réfléchit sur une possible fonction sociale de la sémiologie d'après le travail de Roland Barthes. Ensuite, on considère l'hypothèse selon laquelle le lien de cette fonction avec l'étude systématique de la signification fait signe à une impasse de la sémiologie. Celle-ci, Roland Barthes la prévoit aussi bien qu'il la lit de façon critique. 